\title{
Research Paper: Effect of McKenzie Techniques on Muscle Strengthening in Anterior Knee Pain
}

\author{
Jaleh Farahmand Farzaneh $^{1}$ (D), Mohammad Akbari ${ }^{1^{*}}$ (D), Esmail Ebrahimi Takamjani ${ }^{1}$, Holakoo Mohsenifar ${ }^{1}$
}

1. Department of Physiotherapy, School of Rehabilitation Sciences, Iran University of Medical Sciences, Tehran, Iran.

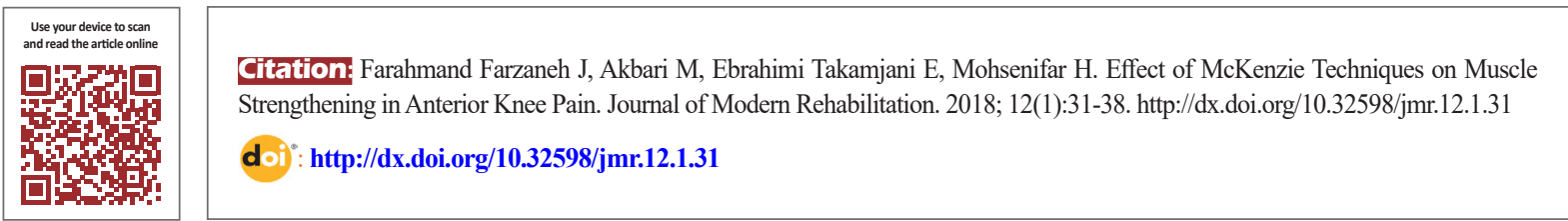

Funding: See Page 36

(c) Copyright: The Author(s)

Article info:

Received: 15 May 2017

Accepted: 06 Oct 2017

Available Online: 01 Jan 2018

\section{Keywords:}

Exercises, Knee pain, Muscle, Strengthening

\section{ABSTRACT}

Introduction: The prevalence of Anterior Knee Pain (ANP) has been reported between $15 \%$ and $45 \%$ in Europe. Muscle weakness is a predisposing factor for ANP. The purpose of this study was to investigate and compare the effect of McKenzie and common exercises on quadriceps and hamstring muscles strengthening and consequently relieving anterior knee pain.

Materials and Methods: A total of 22 patients with ANP (Mean [SD] age: 29.191 [1.658] y) were randomly assigned into control and experiment groups. Each group consisted of 11 subjects. The treatment program included hot pack and acupuncture like TENS modalities for 10 sessions. From the third session, the exercise was added to each group's treatment program separately. The control group exercises consisted of strengthening exercises of the knee, thigh and trunk muscles. In the experiment group, the subjects were initially classified according to mechanical diagnostic tests of McKenzie. This classification is based on patient's response to repetitive movements or constant positions at their end range of motion. The exercise was prescribed according to directional preference which was specific for each case. The strength of quadriceps and hamstring muscles were assessed in three stages with hand held dynamometer. The repeated measure ANOVA test was used to compare variables between two groups. The ANOVA and the Tukey post hoc test were used for intra-group comparisons. All statistical analyses were performed in SPSS V. 21.

Results: The strength of quadriceps muscle in both groups showed a significant improvement $(\mathrm{P}<0.001)$ after the third evaluation. There was no significant difference between the two groups in this regard. There was no significant difference between two groups in hamstring strength among all stages.

Conclusion: In patients with ANP, McKenzie exercises like common exercises can improve the strength of quadriceps muscle. 


\section{Introduction}

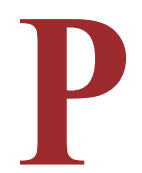

atients may experience Anterior knee Pain (ANP) with or without trauma [1]. Moreover, there is no definitive gold standard method to clinically diagnose ANP [2]. The diagnosis is based on patient's self-report symptoms of diffuse anterior knee pain on activities that load the joint such as squatting, running, climbing and descending stairs [3]. Over the past 20 years, the prevalence of knee pain has increased by $65 \%$ in the United States [4]. Approximately $21 \%-45 \%$ of the physically active adolescents [5] aged between 15 and 30 years and $15 \%-33 \%$ of the adults with a sedentary lifestyle suffer from ANP, with higher incidence and prevalence rates often cited among women $[6,7]$.

A widely accepted theory about the etiology of ANP is excessive stress on the patellofemoral joint [8, 9]. In this regard, Sakai et al. reported that lateral displacement of the patella is observed when vastus medialis is weak. According to them, this finding can be seen in only 0-15 degrees of knee flexion. However, the level of lateralization does not depend on the level of weakness in the vastus medialis muscle [10]. Werner reported that this pain is caused by disturbances in the knee extensor mechanism and quadriceps muscle weakness, especially in the eccentric contraction, in the majority of patients [11].

These findings provided a ground for the treatment of ANP by strengthening of the vastus medialis. Garrick et al. believed that strengthening of the vastus medialis is an important goal in the treatment of anterior knee pain [12]. The vastus medialis and the vastus medialis oblique can be activated differentially and their motor unit recruitment properties are affected by sex and hip position [13]. The appropriate treatment for this syndrome is still unknown, but the most commonly accepted therapeutic intervention is exercise therapy [12, 14-17]. Good clinical results have been achieved with different methods of quadriceps muscle strengthening [12, 18, 19] common exercise therapy for anterior knee pain is knee and hip combination [3]. Repetitive passive movement can be recommended to clinicians for rehabilitation as it provides greater proprioception benefits $[20,21]$. On the other hand, passive physiological movements produce an immediate analgesic effect on deep tissue pain [22].

Exercise therapy, or physical therapy based on exercise [23], is another name for McKenzie methods. In some texts, it is referred to as mechanical diagnosis and therapy. The most important factor in the McKenzie method is postural correction, and the key to treatment in this method is to find the directional preference [24]. In the classification by McKenzie method, the patients are grouped in one of the McKenzie syndromes, including derangement syndrome, articular dysfunction syndrome, contractile dysfunction syndrome, and postural syndrome. Some patients may not be placed in any of the above syndromes and are in the 'other' group [2527], which is the same as contraindications to McKenzie exercises.

There is limited research on the use of McKenzie techniques on the knee. Rosedale conducted the first study of mechanical assessment and treatment using the McKenzie method on the knee joint [28]. However, muscle strength was not assessed in this study. In regard to our review articles there is a study about effects of McKenzie method on muscle strengthening in anterior knee pain subjects, therefore this study aimed to compare the effects of McKenzie and common methods on muscle strengthening in patients with ANP.

\section{Materials and Methods}

This study was a double-blind controlled clinical trial. The study population comprised patients with ANP. A total of 22 subjects with a Mean \pm SD age of $29.91 \pm 1.658$ years, who met the inclusion and exclusion criteria, were randomly assigned to two groups after signing the consent form. The main inclusion criteria were being 16-40 years old; feeling pain in front of the knee for at least two months; having at least 3 pain score using Visual Analog Scale (VAS); having positive response to at least 2 items of the Kujala questionnaire; confirming by specialist; lacking actual knee locking or patellar dislocation; having no history of arthritis, radiographic abnormalities of the knee joint, ligament injury, active infections, previous physiotherapy; avoiding the use of analgesics within 48 hours before the test; and having no anatomical disorders in the chest and upper and lower extremities.

The only exclusion criterion was patient's reluctance to continue the study. A total of 22 individuals were randomly recruited in the study. Odd numbers assigned for control and even numbers for experiment group. The participants were asked to stop taking analgesics during the study. They were assured that their information would be confidential and anonymous. The treatment protocol consisted of ten sessions on a daily basis (even on holidays). Patients in both groups received therapeutic modalities during the first two treatment sessions, including acupuncture like TENS and hot pack. From session 3 , in addition to the above modalities, exercise therapy was added to the program. For each group, a 
training program was designed and explained to the participants, which included the time and number of exercises at home.

The total number of patients who participated in this study was 27 , of whom 5 were excluded due to failure to complete treatment sessions because of personal excuses or lack of access during follow-up. It should be noted that the intervention did not exacerbate the symptoms of the patients. The two groups were matched with respect to gender distribution.

\section{Control group exercises}

First, 5 minutes warm-up was done by walking [29]. Strengthening exercises for the hip (abductors and external rotators) and knees (flexors and extensors) muscles with $50 \%$ of the one-repetition maximum and $20 \%$ increase on a daily basis (against gravity and without weights) [30], as well as strengthening exercises of the trunk with Swiss ball were carried out two times a day. At the end of the session, cooling down was done, including stretching exercises of the hamstring, quadriceps and gastrocnemius muscles. Each exercise was repeated three times and maintained for 5 seconds [29].

\section{Experiment group exercises}

Each patient in this group was evaluated separately using the Mackenzie method and the data were recorded in the McKenzie assessment questionnaire. Based on how to response to active, passive, passive with overpressure, and resistive movements, the type of McKenzie syndromes were determined. In the cases of positive and immediate response (in terms of pain, function or range of motion), the direction or condition of movement was considered the preferred direction. The repetitive flexion or extension of knee movements (for those with derangement syndrome) or static positions at the end of the range of motion (for that dysfunctional syndrome) were performed in directional preference every 2 hours, 10 times in each set. Movements in the opposite direction of preference were banned in this group.

The first step in this group was correction of body position [31], which included two phases: attain and maintain. The attain phase was done using the McKenzie method via "Slouch Overcorrect Relaxed" [23]. The maintain phase included scapular stabilizing exercises and the use of lumbar and cervical McKenzie rolls and stretching of the pectoral muscles. The suggested exercises were as follows:

\section{Doorway Stretch}

This exercise is appropriate to obtain the required flexibility for posture. The patient stands inside the door frame. The elbow is bent 90 degrees along the shoulder. The forearm is placed on the edge of the door frame. The rotation of the trunk is done so that the patient feels the right stretch in the front of the chest and shoulder. This position is held for seven seconds. These exercises were repeated twice per day and 10 times in each set.

\section{Thoracic extension on Foam Roller}

This exercise is done to obtain mobility of the thoracic spine and prevent the slouched position. A foam roller is put under the upper back in supine position and the feet and buttocks are placed on the ground. The hands are positioned behind the head and the elbows are brought together as close as possible. The head is allowed to hit the ground. The person tries to turn himself onto the foam roller and move it up and down the upper part of the back. When hitting the painful points, he lifts his head from the ground and pushes his back to the foam roller and then goes back. This procedure was performed twice a day for 5 minutes.

\section{Prone Y Extension:}

This exercise is to strengthen the lower trapezius muscle and external rotators of the shoulder, a well as to stretch abdominal and chest muscles that are always in the flexion position. Lying in the prone position on the ground with legs as wide apart as the shoulder, the patient puts his arms in a Y shape above his head facing the ground and lifts his torso as an extension and moves the arms outward. This position is maintained for 5 seconds. This exercise was repeated two times per day and 10 times in each set. In addition, throughout the study, the participants in the McKenzie group used the McKenzie lumbar roll or a similar object when sitting and the McKenzie cervical roll while sleeping.

\section{Study tools}

In order to measure the quadriceps and hamstring maximum isometric force (power), a Hand-Held Dynamometer (HHD) [32] was used (Figure 1). The validity and reliability of HHD in lower limb muscles have been reported fair to high in several studies [33-36]. 


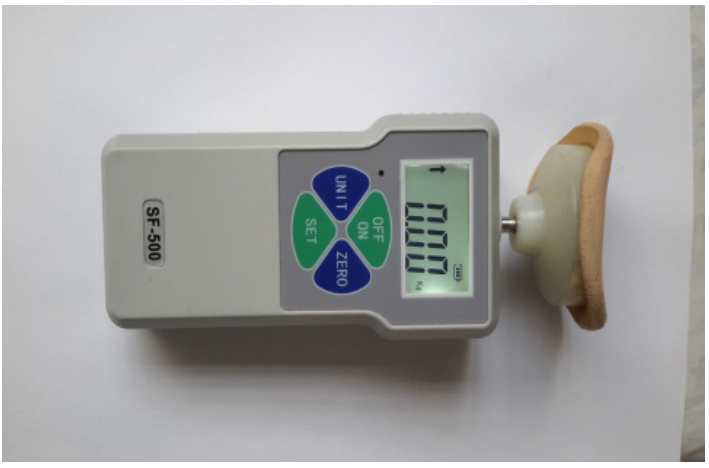

$J \mathrm{MR}$

Figure 1. Hand held dynamometer

\section{Measurement of quadriceps strength}

Patient status: Sitting on the edge of the bed, knees sticking to the edge of the bed, legs hanging from the edge of the bed.

Stabilization: The patient holds the edge of the bed with his hands and his thigh is fixed to the bed with a sling.

In $90^{\circ}$ of knee flexion, the dynamometer is placed at the boundary between the third and fourth quarters of the leg, above the ankle. The patient extends the knee with maximum force and the examiner tries to prevent it. The amount of force applied by the patient is measured by the dynamometer [37] (Figure 2). This measurement was repeated three times and the average reading was recorded as the strength of the quadriceps muscle.

\section{Measurement of hamstring strength}

Patient status: Lying prone with knee flexion. Stabilization: The hip and thigh (middle third) of the patient are fixed to the bed with a sling. In $90^{\circ}, 45^{\circ}$ and $30^{\circ}$ of knee flexion [38], the dynamometer is placed at the boundary between the third and fourth quarters of the leg, above the ankle. The patient flexes the knee with maximum force while the examiner tries to hold it. This measurement was repeated three times and the average of these three readings was recorded as the hamstring muscle strength [38] (Figure 3).

\section{Data analysis}

Statistical analysis was performed by SPSS V. 21. The normal distribution of the data was examined using the Kolmogorov-Smirnov test. The variables of quadriceps and hamstring muscle strength had a normal distribution. To compare the two groups in the three stages, repeated measures ANOVA was employed. The ANOVA

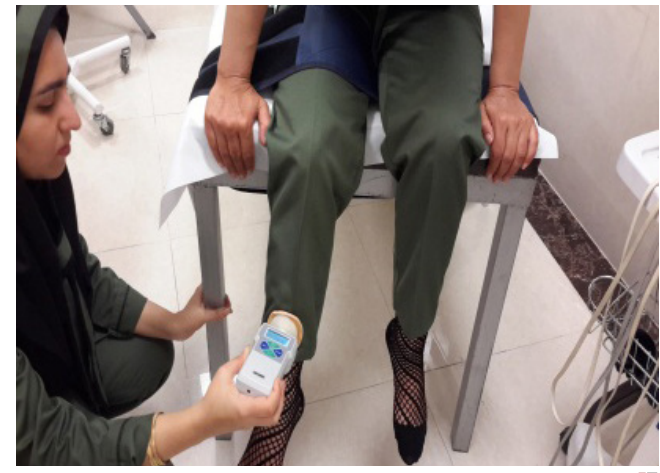

JMR

Figure 2. Quadriceps muscle strength evaluation method

and the Tukey post hoc test were used for intra-group comparisons.

\section{Results}

According to Fisher test, there was no difference between two groups with regard to the distribution of sex, age, weight, height, side of affected knee, and duration of knee pain. There was no significant difference in quadriceps muscle strength between two groups before the intervention $(\mathrm{P}=0.8)$. Repeated measures ANOVA showed no significant difference between the two groups $(\mathrm{P}=0.7)$. The ANOVA test revealed a significant improvement in the quadriceps muscle strength after the intervention, in both groups $(\mathrm{P}<0.001)$ (Table 1$)$. Tukey post hoc test (Table 2) showed no significant difference in quadriceps muscle strength between the first and second evaluation in both groups $(\mathrm{P}=0.7$ and $\mathrm{P}=0.2)$, but there was a significant difference between the first and the third evaluation and between the second and the third evaluation in both groups $(\mathrm{P}<0.001)$.

According to Table 3, 1-way ANOVA showed no significant improvement in hamstring muscle strength in the

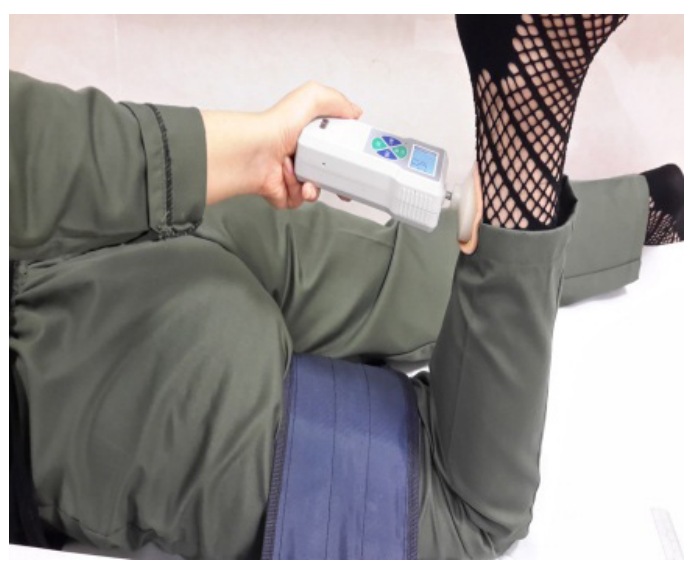

$J M R$

Figure 3. Hamstring muscles strength evaluation method 
Table 1. Results of ANOVA test for quadriceps muscle strength between two groups

\begin{tabular}{ccccc}
\hline Group & Comparison & Mean Square & Degree of Freedom & 2 \\
Control & Between groups & 70.26 & 30 & 0.7 \\
& Within group & 7.34 & 2 & 0.001 \\
Experiment & Between groups & 67.64 & 30 \\
\hline
\end{tabular}

Table 2. Results of Tukey test for quadriceps muscle strength among 3 steps evaluation in two groups

\begin{tabular}{|c|c|c|c|c|}
\hline \multicolumn{2}{|c|}{ Quadriceps Muscle Strength } & \multirow{2}{*}{$\begin{array}{c}\text { Mean } \pm \text { SD of The } \\
\text { Control Group }\end{array}$} & \multirow{2}{*}{$\begin{array}{c}\text { Mean } \pm \text { SD of The } \\
\text { Experiment Group }\end{array}$} & \multirow{2}{*}{$\begin{array}{c}\mathbf{P} \\
0.7\end{array}$} \\
\hline & Evaluation 1-2 & & & \\
\hline \multirow[t]{3}{*}{ Control group } & Evaluation 2-3 & $14.9 \pm 3.4$ & $16.2 \pm 2.5$ & 0.001 \\
\hline & Evaluation 1-3 & $12.08 \pm 2.3$ & $16.2 \pm 2.5$ & 0.001 \\
\hline & Evaluation 1-2 & $11.9 \pm 1.6$ & $15.3 \pm 5.2$ & 0.2 \\
\hline \multirow[t]{2}{*}{ Experiment group } & Evaluation 2-3 & $15.3 \pm 5.2$ & $15.4 \pm 4.2$ & 0.001 \\
\hline & Evaluation 1-3 & $11.9 \pm 1.6$ & $15.4 \pm 4.2$ & 0.001 \\
\hline
\end{tabular}

Repeated measures ANOVA showed that the two groups did not have a significant difference $(\mathrm{P}=0.9)$.

JMR

two groups after the intervention $(\mathrm{P}=0.09$ and $\mathrm{P}=0.5)$. Tukey post hoc test also showed no significant difference in the hamstring strength between the first and the second, the first and the third, and the second and the third evaluation in each group.

\section{Discussion}

The results showed that in patients with ANP, McKenzie exercises similar to common exercises can strengthen the quadriceps muscle. But there was no significant difference in hamstring strength in two groups. One of the reasons for the significant change in quadriceps strength can be attributed to the different effects of quadriceps and hamstring muscles on ANP [39]. Because in these patients, the contraction of the quadriceps muscle faster and more is inhibited. The inhibition of muscle causes more atrophy and weakness in this muscle.

On the other hand, because the quadriceps muscle contraction leads to increase in the compression between patella and femoral groove, therefore it can aggravate ANP and consequently a vicious cycle including pain, inhibition of muscle contraction, facilitation of the quadriceps muscle atrophy, and finally its weakness. During physiotherapy, we tried to relief pain and maintain the knee in the correct and pain-less position and simultaneously doing strengthening exercise to break the vicious cycle. Therefore quadriceps muscle strength improved significantly. But the foregoing items do not apply to

Table 3. Results of ANOVA test for hamstring muscle strength between two groups

\begin{tabular}{ccccc}
\hline Group & Comparison & Mean Square & Degree of Freedom & P \\
\hline \multirow{2}{*}{ Control } & Between groups & 19.26 & 2 & 0.9 \\
& Within group & 7.08 & 30 & 0.09 \\
\multirow{2}{*}{ Experiment } & Between groups & 6.01 & 2 & 0.9 \\
& Within group & 8.38 & 30 & 0.5
\end{tabular}


hamstrings in patients with ANP. Lankhorst et al. reported that the weakness of the quadriceps is a predisposing factor for ANP [40].

The hamstring muscle is not so responsible for ANP. The results of Lankhorst study are similar to our study. The researcher could not find a study with the findings contrary to this study. In addition, the number of exercises available to strengthen the quadriceps muscle in ANP is several times that of hamstring muscle exercises. This can also be another reason for the difference between quadriceps and hamstring strengthening in this study. Furthermore the postural exercises prescribed in this study, emphasize the increase in antigravity muscle strength; the quadriceps muscle is an antigravity muscle [41].

Although the early increase in maximal motor unit discharge rate with repeated maximal force exercise may comprise an important neural mechanism mediating early, rapid gains in muscular force capability [42]. Regarding the results of this study, McKenzie method and common exercises method have similar effect on the strength of the quadriceps and hamstring muscles and consequently ANP.

\section{Ethical Considerations}

\section{Compliance with ethical guidelines}

This study has been approved by the Ethics Committee of Iran University of Medical Sciences (Code: IR.IUMS. REC 1397.94114009).

\section{Funding}

The authors wish to thank Vice Chancellor for Research and Technology of Iran University of Medical Sciences for funding the study.

\section{Conflict of interest}

The authors declare no conflict of interest.

\section{Acknowledgments}

The authors wish to thank all volunteers whom took part in this study.

\section{References}

[1] Callaghan MJ, Selfe J. Has the incidence or prevalence of patellofemoral pain in the general population in the United Kingdom been properly evaluated? Physical Therapy in Sport. 2007; 8(1):37-43. [DOI:10.1016/j.ptsp.2006.07.001]

[2] Nunes GS, Stapait EL, Kirsten MH, de Noronha M, Santos GM. Clinical test for diagnosis of patellofemoral pain syndrome: Systematic review with meta-analysis. Physical therapy in sport : Official Journal of the Association of Chartered Physiotherapists in Sports Medicine. 2013; 14(1):54-9. [DOI:10.1016/j.ptsp.2012.11.003] [PMID]

[3] Crossley KM, Stefanik JJ, Selfe J, Collins NJ, Davis IS, Powers CM, et al. 2016 Patellofemoral pain consensus statement from the $4^{\text {th }}$ International Patellofemoral Pain Research Retreat, Manchester. Part 1: Terminology, definitions, clinical examination, natural history, patellofemoral osteoarthritis and patient-reported outcome measures. British Journal of Sports Medicine. 2016; 50(14):839-43. [DOI:10.1136/bjss ports-2016-096384] [PMID] [PMCID]

[4] Nguyen USD, Zhang Y, Zhu Y, Niu J, Zhang B, Felson DT. Increasing prevalence of knee pain and symptomatic knee osteoarthritis: Survey and cohort data. Annals of Internal Medicine. 2011; 155(11):725-32. [DOI:10.7326/0003-4819-15511-201112060-00004] [PMID]

[5] Roush JR, Curtis Bay R. Prevalence of anterior knee pain in 18-35 year-old females. International Journal of Sports Physical Therapy. 2012; 7(4):396-401. [PMID] [PMCID]

[6] Boling M, Padua D, Marshall S, Guskiewicz K, Pyne S, Beutler A. Gender differences in the incidence and prevalence of patellofemoral pain syndrome. Scandinavian Journal of Medicine \& Science in Sports. 2010; 20(5):725-30. [DOI:10.1111/j.1600-0838.2009.00996.x] [PMID] [PMCID]

[7] Rathleff MS, Vicenzino B, Middelkoop M, Graven-Nielsen $\mathrm{T}$, van Linschoten $\mathrm{R}$, Hölmich $\mathrm{P}$, et al. Patellofemoral pain in adolescence and adulthood: Same same, but different? Sports Medicine. 2015; 45(11):1489-95. [DOI:10.1007/s40279-0150364-1] [PMID]

[8] Collado H, Fredericson M. Patellofemoral pain syndrome Clinics in Sports Medicine. 2010; 29(3):379-98. [DOI:10.1016/j. csm.2010.03.012] [PMID]

[9] Dixit S, DiFiori JP, Burton M, Mines B. Management of patellofemoral pain syndrome. American Family Physician. 2007; 75(2):194-202. [PMID]

[10] Sakai N, Luo ZP, Rand JA, An KN. The influence of weakness in the vastus medialis oblique muscle on the patellofemoral joint: An in vitro biomechanical study. Clinical Biomechanics. 2000; 15(5):335-9. [DOI:10.1016/S0268-0033(99)00089-3]

[11] Werner S. Anterior knee pain: An update of physical therapy. Knee Surgery, Sports Traumatology, Arthroscopy. 2014; 22(10):2286-94. [DOI:10.1007/s00167-014-3150-y] [PMID]

[12] Garrick JG. Anterior knee pain (Chondromalacia patellae). The Physician and Sportsmedicine. 1989; 17(1):75-84. [DOI:10 .1080/00913847.1989.11709683] [PMID]

[13] Peng YL, Tenan MS, Griffin L. Hip position and sex differences in motor unit firing patterns of the vastus medialis and vastus medialis oblique in healthy individuals. Journal of Applied Physiology. 2018; 124(6):1438-46. [DOI:10.1152/japp plphysiol.00702.2017] [PMID] 
[14] Clark DI, Downing N, Mitchell J, Coulson L, Syzpryt EP, Doherty M. Physiotherapy for anterior knee pain: A randomised controlled trial. Annals of the Rheumatic Diseases. 2000; 59(9):700-4. [DOI:10.1136/ard.59.9.700] [PMID] [PMCID]

[15] Roush MB, Sevier TL, Wilson JK, Jenkinson DM, Helfst RH, Gehlsen GM, et al. Anterior knee pain: A clinical comparison of rehabilitation methods. Clinical Journal of Sport Medicine: Official Journal of the Canadian Academy of Sport Medicine. 2000; 10(1):22-8. [DOI:10.1097/00042752-20000100000005] [PMID]

[16] Santos TR, Oliveira BA, Ocarino JM, Holt KG, Fonseca ST. Effectiveness of hip muscle strengthening in patellofemoral pain syndrome patients: A systematic review. Brazilian Journal of Physical Therapy. 2015; 19(3):167-76. [DOI:10.1590/ bjpt-rbf.2014.0089] [PMID] [PMCID]

[17] Smith BE, Hendrick P, Bateman M, Moffatt F, Rathleff MS, Selfe J, et al. Current management strategies for patellofemoral pain: An online survey of 99 practising UK physiotherapists. BMC. 2017; 18:181. [DOI:10.1186/s12891-017-1539-8] [PMID] [PMCID]

[18] Giles L, Webster KE, McClelland J, Cook JL. Quadriceps strengthening with and without blood flow restriction in the treatment of patellofemoral pain: A double-blind randomised trial. British Journal of Sports Medicine. 2017; 51(23):1688-94 [DOI:10.1136/bjsports-2016-096329] [PMID]

[19] Powers CM. Rehabilitation of patellofemoral joint disorders: A critical review. The Journal of Orthopaedic and Sports Physical Therapy. 1998; 28(5):345-54. [DOI:10.2519/ jospt.1998.28.5.345] [PMID]

[20] Baek JH, Kim JW, Kim SY, Oh DW, Yoo EY. Acute effect of repeated passive motion exercise on shoulder position sense in patients with hemiplegia: A pilot study. NeuroRehabilitation. 2009; 25(2):101-6. [PMID]

[21] Kwon O, Lee S, Lee Y, Seo D, Jung S, Chol W. The effect of repetitive passive and active movements on proprioception ability in forearm supination. Journal of Physical Therapy Science. 2013; 25(5):587-90. [DOI:10.1589/jpts.25.587] [PMID] [PMCID]

[22] Nielsen MM, Mortensen A, Sorensen JK, Simonsen O, Graven-Nielsen T. Reduction of experimental muscle pain by passive physiological movements. Manual Therapy. 2009; 14(1):101-9. [DOI:10.1016/j.math.2007.12.008] [PMID]

[23] McKenzie RA, May S. The Cervical and thoracic spine: Mechanical diagnosis and therapy. New Zealand: Orthopedic Physical Therapy; 1990.

[24] McKenzie RA, May S. lumbar spine mechanical diagnosis \& therapy. Crichton, New Zealand: Spinal publication; 1990.

[25] Hefford C. McKenzie classification of mechanical spinal pain: profile of syndromes and directions of preference. Manual therapy. 2008; 13(1):75-81. [DOI:10.1016/j. math.2006.08.005] [PMID]

[26] McKenzie RA, May S. Human extremities: Mechanical diagnosis and therapy. New Zealand: Orthopedic Physical Therapy; 2000.

[27] Menon A, May S. Shoulder pain: Differential diagnosis with mechanical diagnosis and therapy extremity assessment- A case report. Manual Therapy. 2013; 18(4):354-7. [DOI:10.1016/j.math.2012.06.011] [PMID]
[28] Rosedale R, Rastogi R, May S, Chesworth BM, Filice F, Willis $\mathrm{S}$, et al. Efficacy of exercise intervention as determined by the McKenzie system of mechanical diagnosis and therapy for knee osteoarthritis: A randomized controlled trial. The Journal of Orthopaedic and Sports Physical Therapy. 2014; 44(3):173-81.

[29] American Heart Association. Healthy For Good [Internet]. 2017 [Updated 2017 June 6]. Available from: http:// www.heart.org/HEARTORG/Affiliate/Healthy-For-Good_ UCM_493007_SubHomePage.jsp

[30] Shimano T, Kraemer WJ, Spiering BA, Volek JS. Relationship between the number of repetitions and selected percentages of one repetition maximum in free weight exercises in trained and untrained men. Journal of Strength and Conditioning Research. 2006; 20(4):819-23. [DOI:10.1519/R-18195.1] [PMID]

[31] Tauchi R, Imagama S, Muramoto A, Tsuboi M, Ishiguro N, Hasegawa Y. Influence of spinal imbalance on knee osteoarthritis in community-living elderly adults. Nagoya Journal of Medical Science. 2015; 77(3):329-37. [PMID] [PMCID]

[32] Hansen EM, McCartney CN, Sweeney RS, Palimenio MR Grindstaff TL. Hand-held dynamometer positioning impacts discomfort during Quadriceps Strength Testing: A validity and reliability study. International Journal of Sports Physical Therapy. 2015; 10(1):62-8. [PMID] [PMCID]

[33] Kollock Jr RO, Onate JA, Van Lunen B. The reliability of portable fixed dynamometry during hip and knee strength assessments. Journal of Athletic Training. 2010; 45(4):349-56. [DOI:10.4085/1062-6050-45.4.349] [PMID] [PMCID]

[34] Moradi Z, Akbari M, Ansari NN, Emrani A, Mohammadi $P$. Strength of hip muscle groups in sedentary women with patellofemoral pain syndrome. Journal of Back and Musculoskeletal Rehabilitation. 2014; 27(3):299-306. [DOI:10.3233/ BMR-130447] [PMID]

[35] Nadler SF, DePrince ML, Hauesien N, Malanga GA, Stitik TP, Price E. Portable dynamometer anchoring station for measuring strength of the hip extensors and abductors. Archives of Physical Medicine and Rehabilitation. 2000; 81(8):1072-6. [DOI:10.1053/apmr.2000.7165] [PMID]

[36] Scott DA, Bond EQ, Sisto SA, Nadler SF. The intra- and interrater reliability of hip muscle strength assessments using a handheld versus a portable dynamometer anchoring station. Archives of Physical Medicine and Rehabilitation. 2004; 85(4):598-603. [DOI:10.1016/j.apmr.2003.07.013] [PMID]

[37] Thorborg K, Petersen J, Magnusson SP, Holmich P. Clinical assessment of hip strength using a hand-held dynamometer is reliable. Scandinavian Journal of Medicine \& Science in Sports. 2010; 20(3):493-501. [DOI:10.1111/j.16000838.2009.00958.x] [PMID]

[38] Kirk EA, Rice CL. Contractile function and motor unit firing rates of the human hamstrings. Journal of Neurophysiology. 2016; 117(1):243-50. [DOI:10.1152/jn.00620.2016] [PMID] [PMCID]

[39] Park J, Hopkins JT. Induced anterior knee pain immediately reduces involuntary and voluntary quadriceps activation. Clinical Journal of Sport Medicine: Official Journal of the Canadian Academy of Sport Medicine. 2013; 23(1):19-24. [DOI:10.1097/JSM.0b013e3182717b7b] [PMID] 
[40] Lankhorst NE, Bierma-Zeinstra SM, van Middelkoop M. Risk factors for patellofemoral pain syndrome: A systematic review. The Journal of Orthopaedic and Sports Physical Therapy. 2012; 42(2):81-94. [DOI:10.2519/jospt.2012.3803] [PMID]

[41] Akbari M, Mousavikhatir R. Changes in the muscle strength and functional performance of healthy women with aging. Medical Journal of the Islamic Republic of Iran. 2012; 26(3):125-31. [PMID] [PMCID]

[42] Kamen G, Knight CA. Training-related adaptations in motor unit discharge rate in young and older adults. The Journals of Gerontology, Series A: Biological Sciences and Medical Sciences. 2004; 59(12):1334-8. [DOI:10.1093/gerona/59.12.1334] 